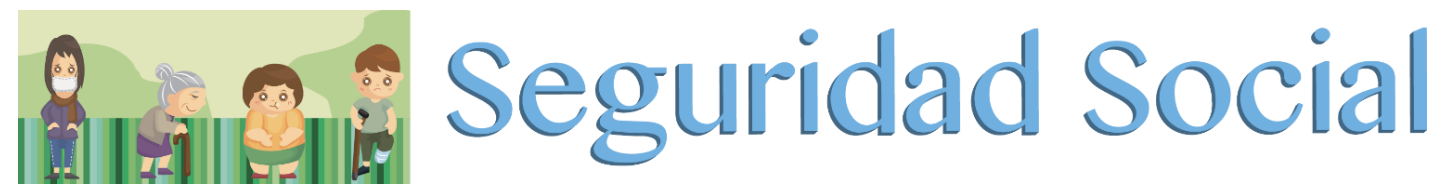

\title{
LA SITUAGIÓN DE LOS HOSPITALES EN 2017
}

Juan Carlos González $\$ \S$

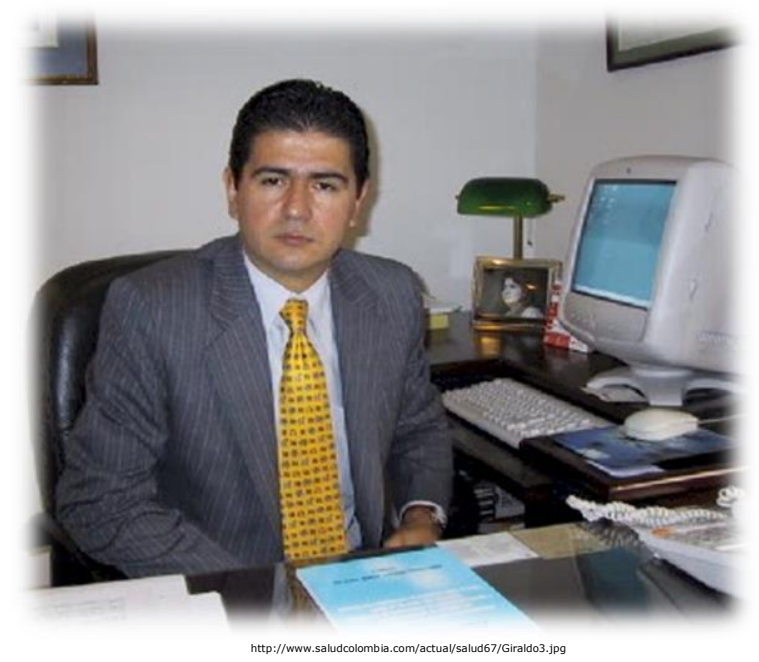

iQué exposición tan clara la que ofreció el doctor Juan Carlos Giraldo en el Congreso de la República acerca del momento que pasan los hospitales! A continuación haremos un breve resumen, insistiéndoles y recomendándoles que, por favor, lo vean a través del link https://www.youtube.com/watch?v=KMQTcUPWNIQ. Es una excelente exposición con una duración de tan solo 10 minutos.

\section{Su punto...}

El gobierno no protege, y no ha protegido lo suficiente al conjunto hospitalario, dejando a los mismos en una precaria situación (yo agrego, a muchos al borde la quiebra).

\section{Datos del sistema hospitalario colombiano}

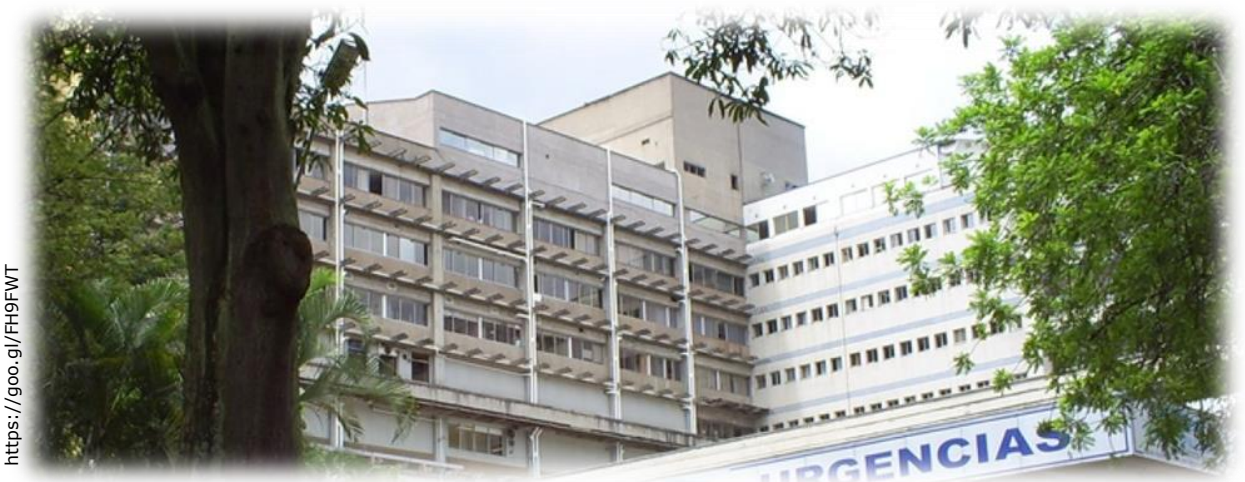

Afirma que existen cerca de 1800 hospitales, $60 \%$ públicos, con cerca de 75000 camas ( 2 de 3 privadas). Generan cerca de 400 000 empleos y 200000 indirectos. Muchos de estos hospitales han de sostenerse de las asignaciones presupuestales históricas a hacerlo de la venta de servicios.

§§ MD. Especialista Medicina Familiar Integral, MSP. Director Departamento de Medicina Comunitaria - juan.gonzalez@juanncorpas.edu.co 


\section{Sus gastos}

El $60 \%$ es nómina y el resto en los insumos para funcionar. Cumplen una labor social inmensa todos, y, algunos, además, se sostienen de la docencia y de la investigación. En el país, algunos son reconocidos incluso a nivel mundial por la calidad de la atención.

\section{El problema: la crisis hospitalaria}

Definida como un desbalance entre los ingresos (menos) y los gastos (más). En el caso colombiano esto es por una causa, a saber, el flujo de recursos del sistema no funciona y no llega a los hospitales cuando (se atrasa o no llega) y como debería (cuando llega es menos que lo facturado) llegar.

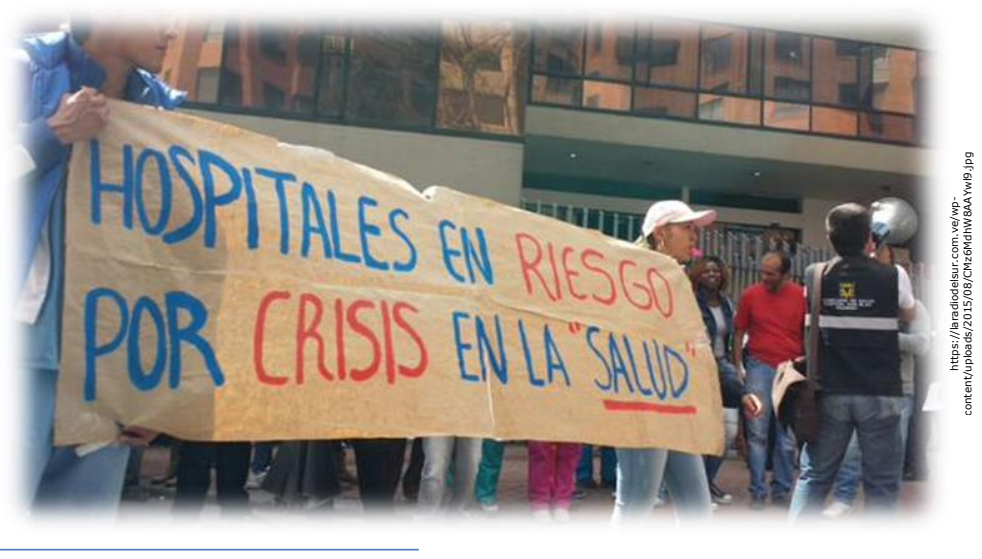

\section{Resultado: cartera hospitalaria}

Afirma el doctor Giraldo que lo que sabe, a través del Observatorio de la Salud, es que para el momento (junio de 2017) la deuda es de 7.3 billones (7.300.000.000.000). Reconoce y nombra los deudores, tales como Nueva EPS, Coomeva y el extinto Cafesalud (con su cola de Saludcoop), así como, en el subsidiado, Savia Salud y Caprecom...

\section{Consecuencias de esa cartera}

\section{Las deudas a los hospitales y clínicas superaron los}

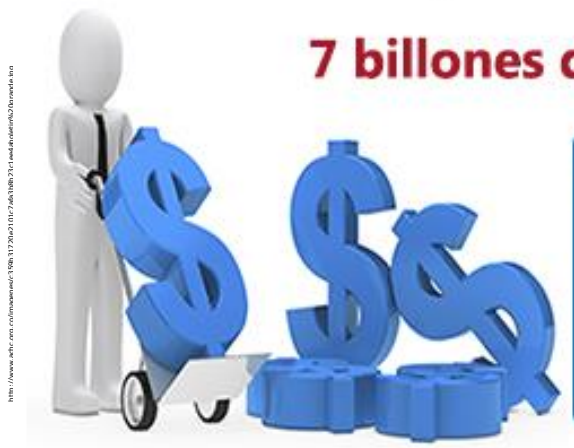

\section{Reforma Tributaria debe \\ contemplar medidas \\ para resolver \\ crisis del sector salud}

A través de entrevistas a más de 170 gerentes de la Asociación Colombiana de Clínicas y Hospitales afirman:

- 1 de 4 afirma que se atrasa más de un mes en el pago de su personal.

- 1 de 3 dice que tuvo que despedir personal.

- El 50 \% dijo que pararon sus programas de capacitación y formación de personal.

- El 80 \% está atrasado con sus proveedores.
- 2 de 3 afirman que han perdido proveedores por no poder cumplir incluso con acuerdos.

- 9 de 10 dejaron de actualizar equipos.

- 7 de 10 tuvieron que adquirir préstamos para poder funcionar.

- 1 de 3 afirma que ha tenido que reducir servicios (cierre y pérdidas de camas).

Carta Comunitaria. Vol. 25. Número 145. Octubre-Diciembre 2017 


\section{Pero, para ser más claros...}

1 de 4 hospitales está en riesgo grande de cerrar.

\section{Como si fuera poco...}

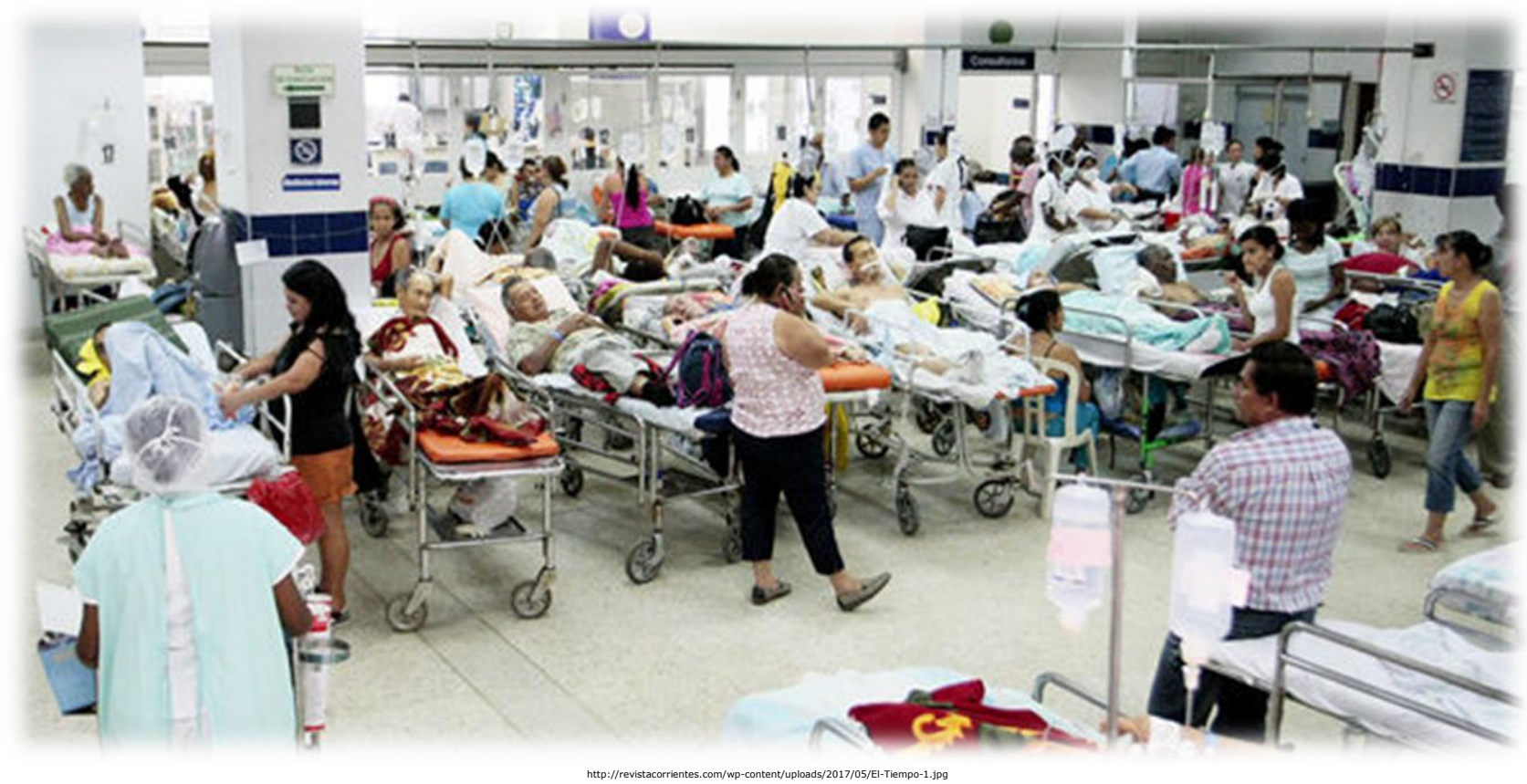

Afirma el doctor Giraldo que Colombia tiene la enfermedad "disparada" y, por ende, la atención de enfermos, lo cual determina que la demanda de la atención hospitalaria vaya en aumento, dando como resultado una congestión aun mayor de servicios como urgencias y, de seguro, como consecuencia de esa sobrecarga, hoy 1 de 6 prestadores en urgencias, afirma haber sido agredido por los pacientes.

\section{Y la calidad ¿qué?}

Afirma que existe un gran cuestionamiento entre los 40 hospitales acreditados, ya que tal certificación no ha implicado nada distinto a las inversiones pertinentes (no asegura ni contratos ni pagos) aseverando que tal proceso de calidad no va a ser asumido por la mayoría de las restantes hospitales y clínicas hasta que se tenga un futuro claro en la prestación. En síntesis, y bajo las condiciones actuales de no pagos, la calidad queda relegada.

\section{Una circular contradictoria}

Menciona la paradoja de la Circular 13 de 2016 de la Superintendencia de Salud, que obliga a que la atención al interior de las IPS sea completa para los pacientes, pero afirma que las EPS se aprovechan de eso, sin comprometerse con el pago respectivo derivado de tales atenciones.

\section{Llama la atención}

Critica las "megaliquidaciones" (Saludcoop, Cafesalud y Caprecom), las cuales se han convertido en una pérdida inmensa de recursos de los hospitales ya que, a través de maromas leguleyas, los mismos liquidadores desconocen los compromisos adquiridos. 


\section{Cuidado con la pérdida de identidad}

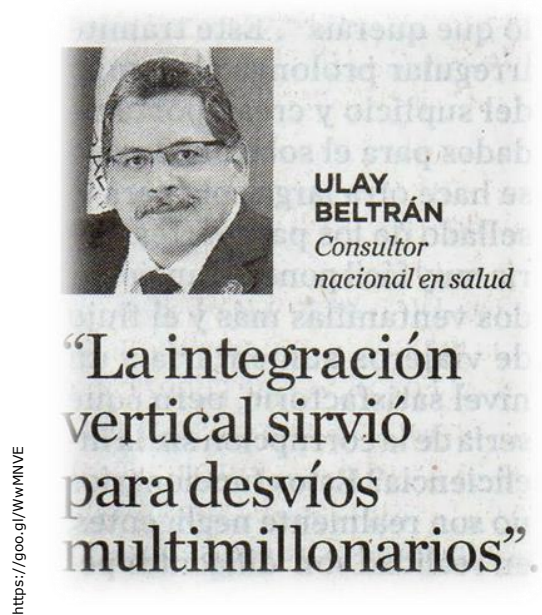

Finalizó su contundente exposición, afirmando que se está promoviendo un desarrollo peligroso cuando se toma el conglomerado de hospitales a los que el sistema les debe inmensas cantidades y se les propone que se transformen en EPS, haciendo que pierdan su identidad, que asuman riesgos de lo que no conocen y promueven la peligrosa y monopólica integración vertical que, en últimas, aleja a los hospitales de su misión fundamental como es atender a los enfermos.

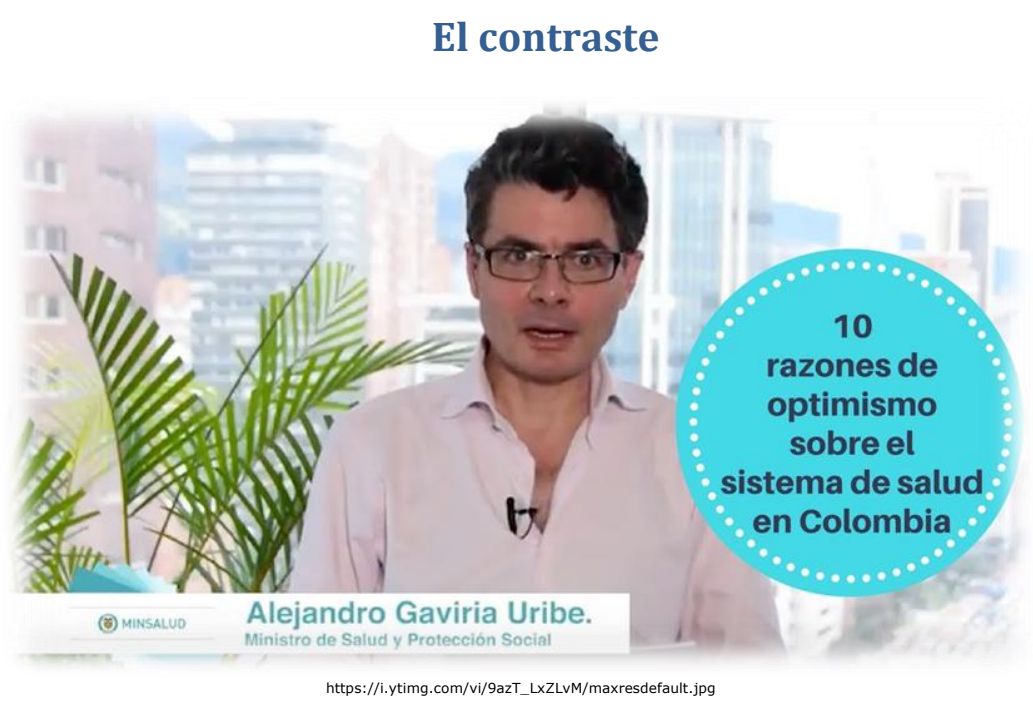

Más o menos para la misma época de la exposición del doctor Giraldo, el Ministro de Salud expuso sus diez razones para estar optimistas. iQué contrastes! Los invitamos a oír sus razones en la dirección https://www.youtube.com/watch?v=9azT_LxZLvM. Será motivo de un próximo artículo este contraste tan interesante.

Definitivamente hay muchas formas de ver el mismo mundo.

\section{Un comentario del editor}

No deja de ser absurdo que no se pague la atención. ¿Cómo puede funcionar un hospital o un centro de salud sin que reciba recursos? La respuesta es obvia. iNo puede! Pretender que el sistema funcione sin cancelarle los gastos a los prestadores es imposible $y$, creer que el sistema puede ser bueno sin pagarle a los prestadores, es absurdo. Por donde se mire, lo primero que se debe garantizar es el cubrimiento de los costos de la prestación, ¿̇o es que existe otra prioridad? Si es así, ¿cuál podrá ser?

Diseñar un modelo de salud basado en la Atención Primaria, a pesar de lo necesario, no es en este momento la prioridad, la que sin duda, es asegurar el pago por la prestación. 